\title{
The identification of liver cirrhosis with modified LBP grayscaling and Otsu binarization
}

\author{
Karan Aggarwal ${ }^{1 *}$, Manjit Singh Bhamrah ${ }^{1}$ and Hardeep Singh Ryait ${ }^{2}$
}

*Correspondence:

karan.170987@gmail.com

${ }^{1}$ Department of Electronics

and Communication

Engineering, Punjabi

University, Patiala, India

Full list of author information

is available at the end of the article

\begin{abstract}
Liver cirrhosis is considered as one of the most common diseases in healthcare. The widely accepted technology for the diagnosis of liver cirrhosis is via ultrasound imaging. This paper presents a technique for detecting the cirrhosis of liver through ultrasound images. The region of interest has been selected from these ultrasound images and endorsed from a radiologist. The identification of liver cirrhosis is finally detected through modified local binary pattern and OTSU methods. Experimental results from the proposed method demonstrated its feasibility and applicability for high performance cirrhotic liver identification.
\end{abstract}

Keywords: Cirrhotic liver, Ultrasound image, Differential local binary pattern

\section{Background}

World Health Organization (WHO) states that 130-150 million people globally have chronic hepatitis $\mathrm{C}$ infection. Lot many those patients may develop liver cirrhosis due to poor medical attention (WHO 2015). Cirrhosis is considered to be the end stage of chronic hepatopathies which may leads to hepatocellular carcinoma (Virmani et al. 2013). The diagnosis of the liver cirrhosis is best achieved by looking at the granular structure of the liver parenchyma and the aspects of the liver surface such as its unevenness and roughness (Virmani et al. 2011). Ultrasound imaging techniques are widely used to diagnose liver cirrhosis using the advanced image processing tools and techniques.

In the present medical scenario, a physician's experience matters to diagnose the cirrhosis where often it is felt that assistive technologies must be developed to improve ultrasound images. Therefore, researchers have been actively exploring the quantitative method to characterize and analyze the different stages of cirrhotic liver (Fujino et al. 2014). Biopsy is considered as "golden standard" for diagnosing diffuse liver diseases, but being in vivo in nature usually not easily accepted the patient. Ultrasonography is the most preferred examination for screening, mainly due to its noninvasive and nonradioactive nature (Jeong et al. 2007). Here, it has been established by the radiologist that the texture of the body tissues provides an important visual property in classification and characterization of results in their radiological significant (Mitrea et al. 2012).

(c) 2016 Aggarwal et al. This article is distributed under the terms of the Creative Commons Attribution 4.0 International License (http://creativecommons.org/licenses/by/4.0/), which permits unrestricted use, distribution, and reproduction in any medium, provided you give appropriate credit to the original author(s) and the source, provide a link to the Creative Commons license, and indicate if changes were made. 
Image texture can be qualitatively defined in following categories of fineness, coarseness, smoothness, surface granulation, randomness, irregular or hummocky (Hawlick 1979). In the textural images, the intensity and spatial arrangement of pixels describes all the above mentioned features (Castellano et al. 2004). This irregular pattern/hummocky is due to rough as well as eruptions/sores/scares on the surface of cirrhotic liver. The regular pattern in normal liver and irregular pattern in cirrhotic liver is shown in Fig. 1a.

Image texture can be qualitatively defined in following categories of fineness, coarseness, smoothness, surface granulation, randomness, irregular or hummocky. In the textural images, the intensity and spatial arrangement of pixels describes all the above mentioned features.

The most common pattern or hummocky of human liver disease is micronodular cirrhosis, a condition characterized by fibrosis and the conversion of normal liver architecture into uniform sized regenerating small nodules. Microscopically, normal liver architecture is distorted by scar tissue which forms a band of connecting tissue joining the periportal and perivenous areas. It is often said that micronodular cirrhosis may be converted into cirrhosis of macronodular type (Fauerholdt et al. 1983). The progression may lead to complete cirrhosis. This becomes a very tedious job to differentiate the change when ultrasound scanning is done. Radiologist needs a very critical analysis to differentiate between these two. If a diagnostic tool can be developed based on the concept of image processing, early disease detection is possible.

Of course, ultrasound images are to be taken for spatial domain analysis as texture differentiation appears to be the vital parameter (Lee 2013; Wu et al. 2012, 2013). Here, the main problem lies in identifying smaller granular or hummocky bodies (about the size of millet seed measuring from 1 to $2.5 \mathrm{~mm}$ in diameter) in case of normal liver and substantially, clustered and inflammatted matrices of granular hummocky bodies (because of scarring) for the case of Cirrhotic Liver. The widely accepted techniques in spatial domain are LBP and OTSU methods. LBP technique reduces a grayscale image to mean weighted grayscale image i.e. grayscale value of central pixel is calculated as per the mean of its surrounding pixels which is defined by the radius parameter of LBP technique.

Regeneration of the ultrasound image on the basis of local binary patterns (LBP) technique has been applied to various uniform texture patterns detection (Brunenberg et al. 2006; Caballero et al. 2006; Keramidas et al. 2007; Pujol et al. 2003). The most important properties of LBP are its tolerance regarding monotonic illumination changes and its computational simplicity. LBP was originally proposed for texture analysis (Ojala et al.
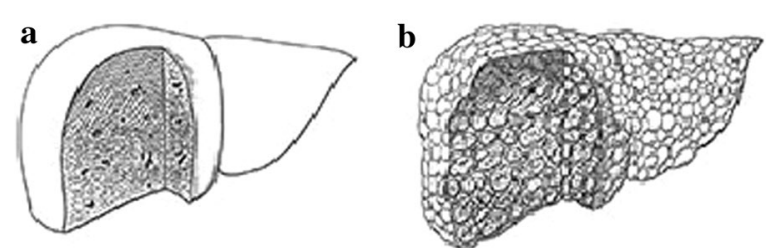

Fig. 1 a Normal liver, b cirrhosis liver: provided by National Institute of Diabetes and Digestive and Kidney Diseases, National Institutes of Health (NIDDK 2010) 
1996) and hence proved to be a simple yet powerful approach to describe local structures. It has been extensively exploited in many applications, for instance, face image analysis (Ahonen et al. 2004; Hadid et al. 2004), image and video retrieval (Huijsmans and Sebe 2003; Grangier and Bengio 2008), environment modeling (Ali et al. 2008; Nanni and Lumini 2008), visual inspection (Maenpaa et al. 2003; Turtinen et al. 2006), motion analysis (Heikkila and Pietikainen 2006; Kellokumpu et al. 2008), biomedical and aerial image analysis (Oliver et al. 2007; Kluckner et al. 2007), and remote sensing (Lucieer et al. 2005). However, this very technique can be seen very useful for cirrhotic liver images obtained through ultrasound.

On the other hand, Otsu's method (Rodríguez 2006; Huang and Wang 2009) a highspeed and effective thresholding approach is applied for image binarization. In this method, it is mainly exploited to discriminate the background and objects on a gray level histogram. It has indeed the advantage to be highly efficient and demands less computation time when the number of classes is two (Tamim et al. 2015; Filipczuk et al. 2013).

The present research work is an effort to detect and classify liver cirrhosis based on their structure and texture pattern retrieved from USI. During the past few years, LBP has aroused increasing interest in image processing and computer vision due to its nature of nonparametric method and Otsu method has the capability in changing grayscale images to binary images using adaptive thresholding. That's why OTSU is additionally added to LBP generated weighted gray scale image. OTSU is doing its normal job but it is applied not to the original image but to the modified LBP image. This modification of LBP method is represented as differential local binary pattern (DLBP) in our further discussion.

\section{Methodology}

The US images were acquired from radiology center under supervision of an experienced radiologist. The ultrasound images each of size 381 by 331 in JPG format were specified in two categories as normal and cirrhotic liver. All the images were acquired from same ultrasound machine to nullify the effects of change in dimensions and texture values on the images which may have happened if it is taken by different sources. The ultrasound probe used for acquiring these images was having depth of $15 \mathrm{~cm}$ and frequency of $5 \mathrm{MHz}$. Radiologist also specified the portion in the images which belonged to cirrhosis as shown in Fig. 2 for cross evaluation. Region of interest (ROI) has been selected as templates of size $50 \times 50$ each from both normal liver and cirrhotic liver ultrasound images as in Fig. 2a-d.

Accordingly, one template was selected from each image, i.e. total of 6 templates were taken from 6 images of normal liver. Similarly, 44 templates were selected from 44 images of cirrhotic liver. Modified LBP with OTSU approach was applied on to the selected templates of both normal and cirrhotic liver.

Ojala et al. (2002) presented the LBP operator for texture classification. LBP operator is that value of the pixel where the accumulative value is calculated from comparing its gray value with its neighbors as given in Eq. (1).

$$
L B P_{P, R}\left(x_{c}, y_{c}\right)=\sum_{p=1}^{P} s\left(g_{p}-g_{c}\right) 2^{P-1}
$$




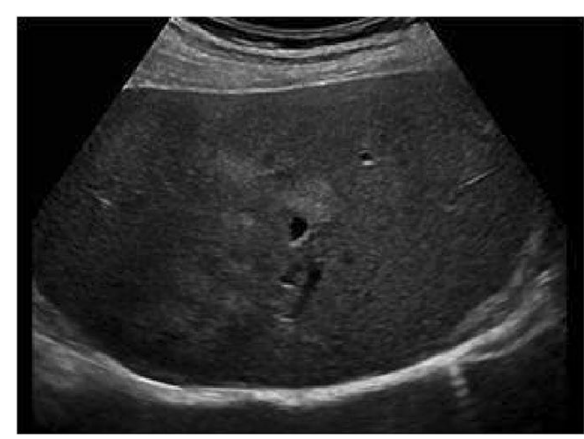

$\mathbf{a}$

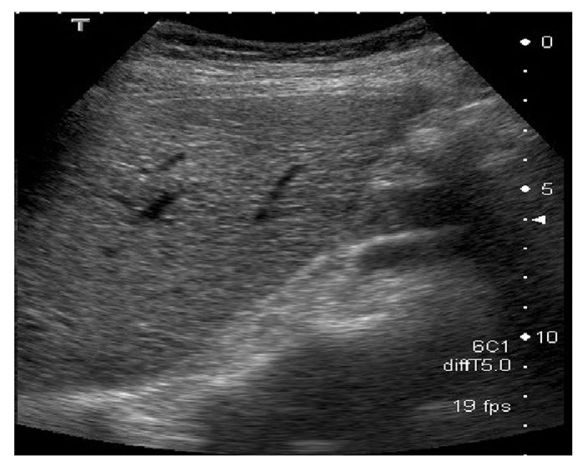

c

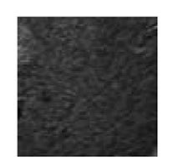

b

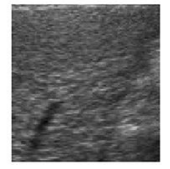

d

Fig. 2 a Ultrasound image of normal liver, b ROI defined by radiologist from normal liver, c ultrasound image of cirrhosis liver, $\mathbf{d}$ ROI defined by radiologist from cirrhosis liver

where

$$
s(z)= \begin{cases}1, & z \geq 0 \\ 0, & z<0\end{cases}
$$

where $g_{c}$ is the gray value of the center pixel, $g_{p}$ is the gray value of neighbor at radius $R$ from the center pixel $\left(g_{c}\right)$ and $P$ is the number of neighbors at a distance (radius) $R$ from the center pixel $\left(g_{c}\right)$ in an image. Examples of such circular neighbor sets for different configurations of $(P, R)$ are shown in Fig. 3. The LBP operator when processed onto the entire image creates new LBP image with desired intensity at each pixels. The concept used to get this desired intensity at pixel level is:

If the gray level of the neighboring pixel is higher or equal to the center pixel, the value is set to one otherwise the value is zero.

Otsu's method is a clustering-based image thresholding, which is based on the selection of the optimal thresholds from the gray-level histogram of an image that maximizes the between-class variance (Fukunage 1972). Otsu defines the between-class variance using the discriminate analysis based on statistics of the 1-D histogram (Otsu 1979).

Assuming an image with the size $\mathrm{M} \times \mathrm{N}$ and gray range $\mathrm{L}$, the number of pixels at gray level $i$ is denoted by $n_{i}$, thus the probability of gray level $i$ can be gained by

$$
\mathrm{P}_{\mathrm{i}}=\mathrm{n}_{\mathrm{i}} /(\mathrm{M} \times \mathrm{N}), \quad \mathrm{P}_{\mathrm{i}} \geq 0 ; \quad \sum_{0}^{\mathrm{L}-1} \mathrm{P}_{\mathrm{i}}=1
$$




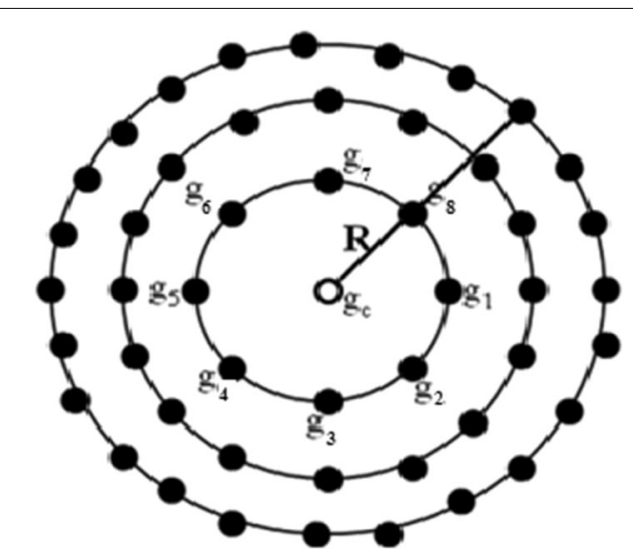

Fig. 3 Circular neighborhood set for different $(P, R)$

If we divide the pixels of the image into two classes of object $C_{0}$ and background $C_{1}$ by the threshold $t$, the gray level probability distributions for the two classes can be expressed by

$$
\begin{aligned}
& \omega_{0}=\mathrm{P}_{\mathrm{r}}\left(\mathrm{C}_{0}\right)=\sum_{\mathrm{i}=0}^{\mathrm{t}} \mathrm{P}_{\mathrm{i}}=\omega(\mathrm{t}) \\
& \omega_{1}=\mathrm{P}_{\mathrm{r}}\left(\mathrm{C}_{1}\right)=\sum_{\mathrm{i}=\mathrm{t}+1}^{\mathrm{L}-1} \mathrm{P}_{\mathrm{i}}=1-\omega(\mathrm{t})
\end{aligned}
$$

The gray means of the class $\mathrm{C}_{0}$ and $\mathrm{C}_{1}$ are

$$
\begin{aligned}
& \mu_{0}=\sum_{\mathrm{i}=0}^{\mathrm{t}} \mathrm{iP}_{\mathrm{r}} / \omega_{0}=\mu(\mathrm{t}) / \omega(\mathrm{t}) \\
& \mu_{1}=\sum_{\mathrm{i}=\mathrm{t}+1}^{\mathrm{L}-1} \mathrm{iP}_{\mathrm{r}} / \omega_{1}=\frac{\mu_{\mathrm{T}}-\mu(\mathrm{t})}{1-\omega(\mathrm{t})}
\end{aligned}
$$

where $\omega(\mathrm{t})=\sum_{\mathrm{i}=0}^{\mathrm{t}} \mathrm{P}_{\mathrm{i}}, \mu(\mathrm{t})=\sum_{\mathrm{i}=0}^{\mathrm{t}} \mathrm{i} \mathrm{P}_{\mathrm{i}}, \mu_{\mathrm{T}}=\sum_{\mathrm{i}=0}^{\mathrm{L}-1} \mathrm{i} \mathrm{P}_{\mathrm{i}}$.

The between-cluster variance of the class $\mathrm{C}_{0}$ and $\mathrm{C}_{1}$ can be given by

$$
\sigma_{\mathrm{B}}^{2}\left(\mathrm{t}^{*}\right)=\omega_{0}\left(\mu_{0}-\mu_{\mathrm{T}}\right)^{2}+\omega_{1}\left(\mu_{1}-\mu_{\mathrm{T}}\right)^{2}
$$

During the image segmentation process by the OTSU method, the between-cluster variance is considered as an important index for the uniformity of gray distributions (Chaou et al. 2015). The larger the between class variance is, the greater the difference between the two classes becomes. The optimal threshold $t^{*}$ can be figured out through maximizing the between-class variance $\sigma_{B}$.

$$
\sigma_{B}^{2}\left(t^{*}\right)=\sum_{\mathrm{t}=0}^{\mathrm{L}-1} \operatorname{Max}\left\{\sigma_{B}^{2}(t)\right\}
$$

Being a nonparametric approach, LBP summarizes local structures of images efficiently by comparing each pixel with its neighboring pixels (Murala and Jonathan 2014; $\mathrm{Hu}$ and Zhao 2010). Here, it is important to mark the radius i.e. $R$ for the computation of LBP operator. 
In the present study, a technique for detecting the liver cirrhosis through ultrasound images has been developed by exploiting LBP operator's computing principle. Widely used local binary pattern encodes the relationship among the surrounding neighbors for a given referenced pixel in an image. The possible relationships among the surrounding neighbors are depending on the number of neighbors. The LBP approach has been observed as a good approach for texture analysis of regular pattern. Hence, found to be advantageous for simultaneously classification between a regular and an irregular pattern.

LBP technique has been slightly modified in terms of difference value between neighboring pixels and centre pixel. The modified approach is:

If the difference value is less than or equal to standard deviation of that matrix then difference value is replace by 0 and otherwise the difference value is replace by one.

Hence, the macro granular in the hummocky type structure of liver appears in the form of black portion in the binary images. Therefore, a technique is needed so that binarization and thresholding becomes so accurate to figure out difference between the normal and cirrhotic liver.

Now if the dimension or size of these black portions can be calculated in terms of no. of consecutive pixels either horizontally or vertically placed, classify between a normal texture and cirrhotic texture is possible.

In the present work the ideology used is to measure black portion or spot or granular as count of horizontally connected black pixels. This count is called here as connectivity. The concept is further extended by counting three such consecutive pixels then four and lastly five such pixels. These 3,4 and 5 connected pixels can further be explored to segregate the stages of cirrhosis. The concept of radius is used to generate spatially equalized LBP grayscale image. Three such selection were made; firstly LBP with radius $=1$, secondly $=2$ and lastly $=3$. Bigger the radius leads to more spatial equalization and thus less chance to detect irregularisation or hummocky type structure.

The same has been projected as an experiment below. In this, Fig. 4a, b were regular and irregular texture images. Figure $4 \mathrm{c}, \mathrm{d}$ were LBPs' images of regular and irregular images respectively. Figure 4e, f were the results after applying OTSU on LBPs' images. Figure $4 \mathrm{~g}$, h were complement of the OTSU images.

If the image is of any regular texture as shown in Fig. 4a then regularity is in its gray level distribution. As first step, Modified LBP approach was applied which removed variation of grayscale and generated Fig. 4e. As there was no abrupt change of grayscale, compliment of 4e becomes a white (blank) image. Therefore, connectivity of black portion comes zero as shown in 4i. Similarly, if any image contains an irregular texture as in Fig. 4b, this means that there is a non-uniform distribution of its grayscale; therefore connecting of the cells will be increased as shown in Fig. 4h. There is a values in 3, 4 as well as in 5 connected pixels as shown the value in Fig. $4 \mathrm{j}$.

In normal liver, because granular or hummocky structure is about uniform in sizes, the value will come very lesser in all 3, 4 or 5 connectivity. If cirrhotic liver is taken, due to the non uniformity, it may appear more. That is the basic of this connectivity. The detailed methodology has been presented in the flow chart shown in Fig. 5. 


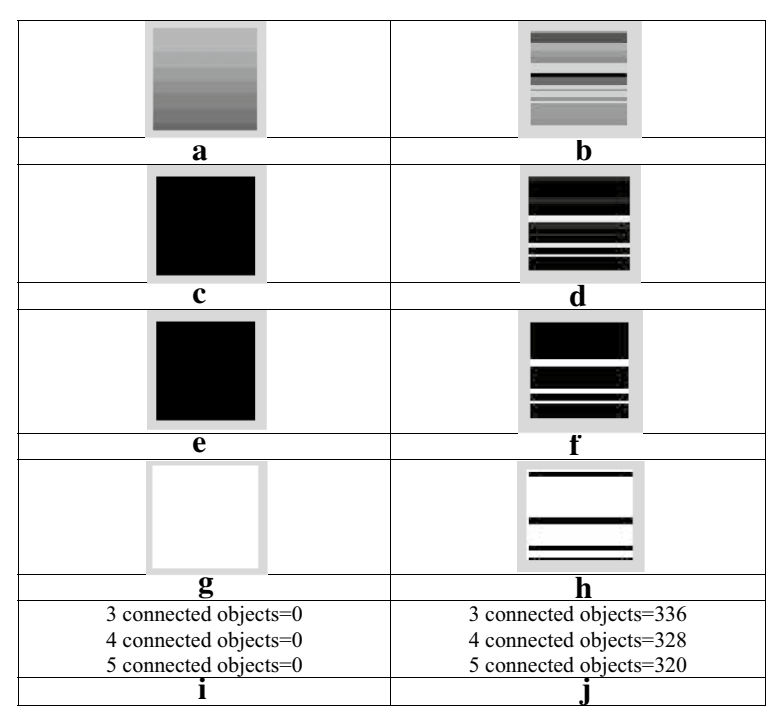

Fig. 4 a, b Regular and irregular texture image, $\mathbf{c}, \mathbf{d} L B P s^{\prime}$ images of regular and irregular images, e, $\mathbf{f}$ OTSU images i.e. results after applying OTSU on both LBPs'images $(\mathbf{g}, \mathbf{h})$ complement of OTSU images $(\mathbf{i}, \mathbf{j})$ values of connected objects for both regular and irregular images

\section{Results and discussion}

Firstly, by applying Otsu method directly to the all templates and get these all 3, 4 and 5 connected counts as shown in Table 1. This method is not giving any specific result.

Secondly, standard LBP is used and Otsu method is applied on that LBP images. LBP radius $(\mathrm{R})$ is used to compute the $\mathrm{LBP}$ operator as shown in Fig. 3. If radius $(\mathrm{R})$ is 1,2 and 3 then matrix become of $3 \times 3,5 \times 5$ and $7 \times 7$ respectively. Then, 3,4 and 5 connected pixels as explained earlier and are getting these all counts for all three radiuses separately as shown in Table 2. There is again no specific result as observed from table.

Finally, modified LBP (DLBP) is used and Otsu method is applied on that DLBP images. Then, again 3, 4 and 5 connected pixels are getting these all counts for all three radiuses separately as shown in Table 3 . This is giving the specific result for identification of liver cirrhosis from normal liver.

As observed from the Table 3, if the counts of 3 connected pixels for radius 1 are $<58$ then the liver is normal liver and if the counts are $>71$ then the liver is cirrhotic liver. Similarly, the counts for 3,4 and 5 connected pixels for radius 1, 2 and 3 are explained in Table 4 for normal liver and cirrhotic liver.

There are some problem in counts for cirrhotic liver because which are assuming as cirrhotic liver that might be at the first stage of cirrhosis i.e. fibrosis. So, further methodology can be amending to stage the cirrhosis. That's why radius 2 and radius 3 is chosen. As the granular and scarring increases that much part is cirrhosis. If it does not lie in the range of cirrhosis then it might be fibrosis.

For statistical interpretation, widely accepted classifiers are used. Here, two classifiers have been selected; one is support vector machine (SVM) and other one is K-nearest neighbor (KNN) support vector machine (SVM) has been chosen for the classification task because classifier designs which use regularization like SVM are less prone to over fitting and obtain good generalization performance to a certain extent even without feature space dimensionality reduction. KNN has been chosen because KNN is 


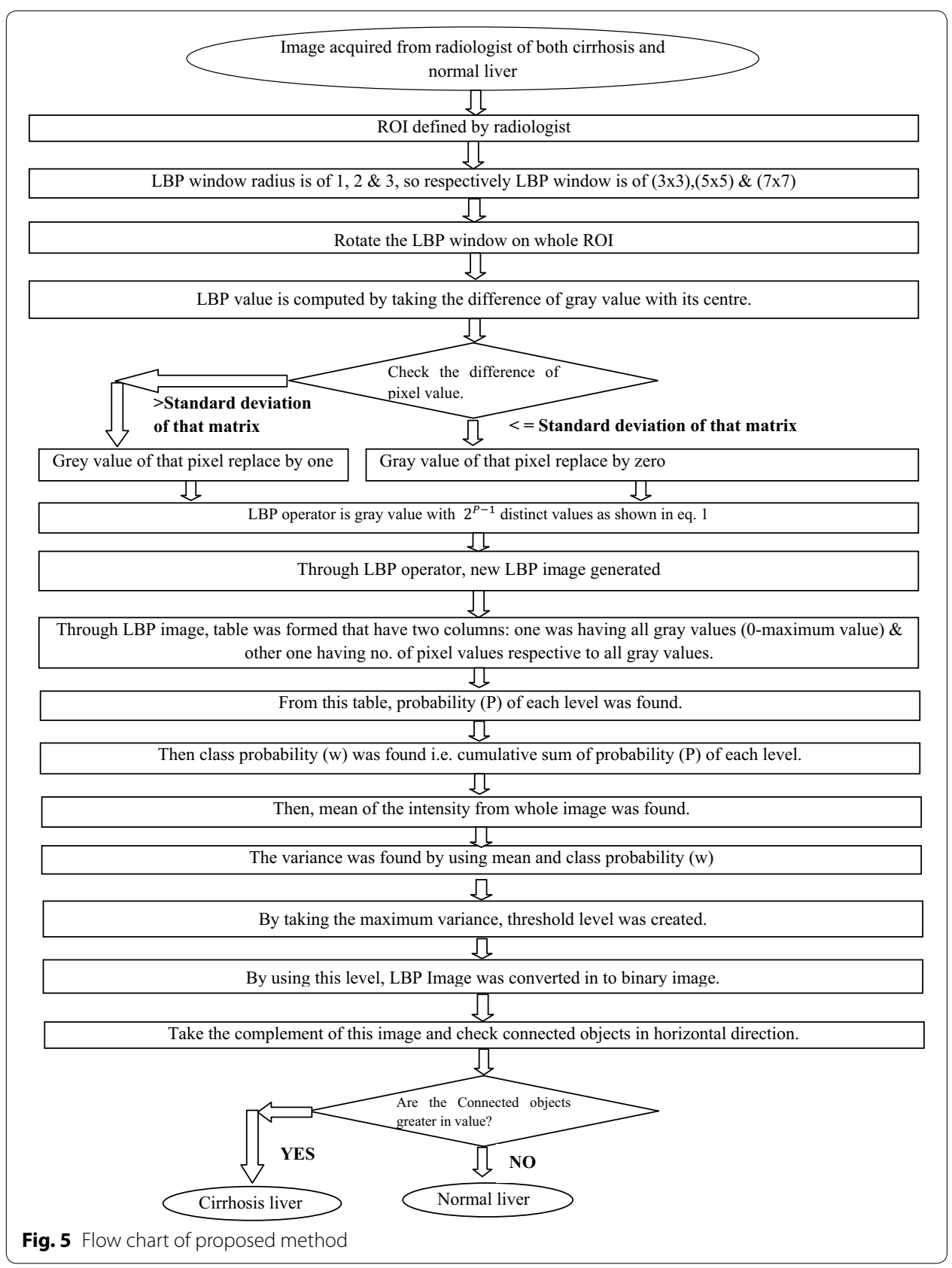

non-parametric, i.e. it makes no assumption about the data distribution. Accuracy of both the classifier will justify our methodology and decision.

Figures 6 and 7 are the classifications of OTSU with LBP method and OTSU with DLBP method respectively. In these classifiers, $x$ axis is 4 connected black objects and $y$ axis is 5 connected black objects for LBP radius of 3 .

In SVM classification of Figs. 6a and 7a, pink plus sign ' + ' indicates the normal liver and blue plus sign ' + ' indicates the cirrhotic liver. The line divides the region of the normal and cirrhotic liver. When OTSU with LBP method is used, there are only 32 out of 
Table 13,4 and 5 connected counts using Otsu method

\begin{tabular}{|c|c|c|c|c|}
\hline $\begin{array}{l}\text { Sr. } \\
\text { No. }\end{array}$ & Liver & $\begin{array}{l}3 \text { connected } \\
\text { black objects }\end{array}$ & $\begin{array}{l}4 \text { connected } \\
\text { black objects }\end{array}$ & $\begin{array}{l}5 \text { connected } \\
\text { black objects }\end{array}$ \\
\hline 1 & Cirrhosis & 0 & 0 & 0 \\
\hline 2 & Cirrhosis & 8 & 2 & 0 \\
\hline 3 & Cirrhosis & 0 & 0 & 0 \\
\hline 4 & Cirrhosis & 65 & 46 & 35 \\
\hline 5 & Cirrhosis & 0 & 0 & 0 \\
\hline 6 & Cirrhosis & 0 & 0 & 0 \\
\hline 7 & Cirrhosis & 0 & 0 & 0 \\
\hline 8 & Cirrhosis & 0 & 0 & 0 \\
\hline 9 & Cirrhosis & 3 & 2 & 1 \\
\hline 10 & Cirrhosis & 12 & 10 & 8 \\
\hline 11 & Cirrhosis & 0 & 0 & 0 \\
\hline 12 & Cirrhosis & 0 & 0 & 0 \\
\hline 13 & Cirrhosis & 0 & 0 & 0 \\
\hline 14 & Cirrhosis & 0 & 0 & 0 \\
\hline 15 & Cirrhosis & 0 & 0 & 0 \\
\hline 16 & Cirrhosis & 0 & 0 & 0 \\
\hline 17 & Cirrhosis & 0 & 0 & 0 \\
\hline 18 & Cirrhosis & 0 & 0 & 0 \\
\hline 19 & Cirrhosis & 0 & 0 & 0 \\
\hline 20 & Cirrhosis & 0 & 0 & 0 \\
\hline 21 & Cirrhosis & 0 & 0 & 0 \\
\hline 22 & Cirrhosis & 0 & 0 & 0 \\
\hline 23 & Cirrhosis & 0 & 0 & 0 \\
\hline 24 & Cirrhosis & 0 & 0 & 0 \\
\hline 25 & Cirrhosis & 0 & 0 & 0 \\
\hline 26 & Cirrhosis & 0 & 0 & 0 \\
\hline 27 & Cirrhosis & 0 & 0 & 0 \\
\hline 28 & Cirrhosis & 0 & 0 & 0 \\
\hline 29 & Cirrhosis & 0 & 0 & 0 \\
\hline 30 & Cirrhosis & 0 & 0 & 0 \\
\hline 31 & Cirrhosis & 1 & 0 & 0 \\
\hline 32 & Cirrhosis & 0 & 0 & 0 \\
\hline 33 & Cirrhosis & 0 & 0 & 0 \\
\hline 34 & Cirrhosis & 0 & 0 & 0 \\
\hline 35 & Cirrhosis & 0 & 0 & 0 \\
\hline 36 & Cirrhosis & 0 & 0 & 0 \\
\hline 37 & Cirrhosis & 0 & 0 & 0 \\
\hline 38 & Cirrhosis & 0 & 0 & 0 \\
\hline 39 & Cirrhosis & 0 & 0 & 0 \\
\hline 40 & Cirrhosis & 24 & 21 & 19 \\
\hline 41 & Cirrhosis & 0 & 0 & 0 \\
\hline 42 & Cirrhosis & 13 & 10 & 7 \\
\hline 43 & Cirrhosis & 0 & 0 & 0 \\
\hline 44 & Cirrhosis & 0 & 0 & 0 \\
\hline 45 & Normal & 0 & 0 & 0 \\
\hline 46 & Normal & 0 & 0 & 0 \\
\hline 47 & Normal & 0 & 0 & 0 \\
\hline 48 & Normal & 0 & 0 & 0 \\
\hline 49 & Normal & 0 & 0 & 0 \\
\hline 50 & Normal & 0 & 0 & 0 \\
\hline
\end{tabular}


44 blue plus signs falls in the cirrhosis region and 5 out of 6 red plus signs in normal region as shown in Fig. 6a. So accuracy is 72.7 \% for the cirrhotic liver and $83.3 \%$ for normal liver of OTSU with LBP method. When OTSU with DLBP is used, there are 42 out of 44 blue plus signs falls in the cirrhosis region and all red plus signs in normal region as shown in Fig. 7a. So accuracy is $95.45 \%$ for the cirrhotic liver and $100 \%$ for normal liver of OTSU with DLBP method.

In KNN classification of Figs. $6 \mathrm{~b}$ and $7 \mathrm{~b}$, blue dots for normal liver and red dots for cirrhotic liver. In this, all blue dots are accumulated together and red dots are accumulated together. In this classification, plus $(+)$ sign is the point that separates the region of cirrhosis and normal liver and circles are the nearest neighbors of this plus (+) sign. When OTSU with LBP method is used, there are 40 out of 44 red dots falls in the cirrhosis region and 2 out of 6 blue dots falls in the normal region as shown in Fig. 6(b). So, accuracy is $90.9 \%$ for the cirrhotic liver and $33.33 \%$ for the normal liver of OTSU with LBP method. When OTSU with DLBP method is used, there are 43 out of 44 red dots falls in the cirrhosis region and 5 out of 6 red dots falls in the normal region as shown in Fig. 7b. So, accuracy is 97.72 \% for the cirrhotic liver and $83.33 \%$ for the normal liver of OTSU with DLBP method. The sensitivity is 97.75 and specificity is $83.3 \%$ of this method.

\begin{tabular}{lll}
\hline Methods & Recognition rate & \\
\cline { 2 - 3 } \cline { 3 - 3 } & Using SVM classifier (\%) & Using KNN classifier (\%) \\
\hline OTSU with LBP method & 72.7 & 90.9 \\
OTSU with DLBP method & 95.45 & 97.72 \\
\hline
\end{tabular}

\section{Conclusions}

In this study, a modified LBP with OTSU method has been proposed for better identification of texture in ultrasound images of liver in which uncertainty is introduced by inherent noise. The proposed inspection technique was evaluated on a real dataset of 44 templates of 44 cirrhotic liver and 6 templates of 6 normal liver ultrasound images. The promising results achieved in detecting cirrhotic liver. SVM classifier has given the accuracy of $95.45 \%$ for cirrhotic liver and $100 \%$ for normal liver. Similarly, KNN has given the accuracy of $97.72 \%$ for cirrhotic liver and $83.3 \%$ for normal liver. The sensitivity is $97.2 \%$ and specificity is $83.3 \%$. In the future study; the performance of this technique can be investigated on ultrasound images to classify different stages of cirrhotic liver. 
Table 2 3, 4 and 5 connected counts using LBP with Otsu method

\begin{tabular}{|c|c|c|c|c|c|c|c|c|c|c|}
\hline \multirow[t]{2}{*}{$\begin{array}{l}\text { Sr. } \\
\text { No. }\end{array}$} & \multirow[t]{2}{*}{ Liver } & \multicolumn{3}{|c|}{$\begin{array}{l}\text { LBP radius }=1, \\
\text { matrix }=3 \times 3\end{array}$} & \multicolumn{3}{|c|}{$\begin{array}{l}\text { LBP radius }=2, \\
\text { matrix }=5 \times 5\end{array}$} & \multicolumn{3}{|c|}{$\begin{array}{l}\text { LBP radius }=3, \\
\text { matrix }=7 \times 7\end{array}$} \\
\hline & & $\begin{array}{l}3 \text { con- } \\
\text { nected } \\
\text { black } \\
\text { objects }\end{array}$ & $\begin{array}{l}4 \text { con- } \\
\text { nected } \\
\text { black } \\
\text { objects }\end{array}$ & $\begin{array}{l}5 \text { con- } \\
\text { nected } \\
\text { black } \\
\text { objects }\end{array}$ & $\begin{array}{l}3 \text { con- } \\
\text { nected } \\
\text { black } \\
\text { objects }\end{array}$ & $\begin{array}{l}4 \text { con- } \\
\text { nected } \\
\text { black } \\
\text { objects }\end{array}$ & $\begin{array}{l}5 \text { con- } \\
\text { nected } \\
\text { black } \\
\text { objects }\end{array}$ & $\begin{array}{l}3 \text { con- } \\
\text { nected } \\
\text { black } \\
\text { objects }\end{array}$ & $\begin{array}{l}4 \text { con- } \\
\text { nected } \\
\text { black } \\
\text { objects }\end{array}$ & $\begin{array}{l}5 \text { con- } \\
\text { nected } \\
\text { black } \\
\text { objects }\end{array}$ \\
\hline 1 & Cirrhosis & 719 & 554 & 419 & 669 & 536 & 426 & 582 & 464 & 363 \\
\hline 2 & Cirrhosis & 624 & 451 & 334 & 556 & 416 & 317 & 520 & 382 & 288 \\
\hline 3 & Cirrhosis & 709 & 542 & 409 & 585 & 451 & 349 & 589 & 469 & 381 \\
\hline 4 & Cirrhosis & 597 & 471 & 369 & 593 & 486 & 396 & 575 & 473 & 393 \\
\hline 5 & Cirrhosis & 597 & 428 & 307 & 572 & 414 & 295 & 491 & 343 & 237 \\
\hline 6 & Cirrhosis & 551 & 387 & 275 & 500 & 357 & 263 & 423 & 267 & 167 \\
\hline 7 & Cirrhosis & 798 & 641 & 515 & 761 & 628 & 518 & 737 & 622 & 526 \\
\hline 8 & Cirrhosis & 713 & 558 & 436 & 682 & 551 & 443 & 626 & 509 & 414 \\
\hline 9 & Cirrhosis & 724 & 566 & 449 & 660 & 520 & 405 & 635 & 499 & 403 \\
\hline 10 & Cirrhosis & 684 & 499 & 369 & 689 & 526 & 409 & 512 & 368 & 271 \\
\hline 11 & Cirrhosis & 594 & 438 & 325 & 567 & 430 & 319 & 536 & 411 & 317 \\
\hline 12 & Cirrhosis & 795 & 659 & 553 & 743 & 618 & 508 & 714 & 589 & 480 \\
\hline 13 & Cirrhosis & 611 & 456 & 345 & 468 & 348 & 252 & 529 & 410 & 323 \\
\hline 14 & Cirrhosis & 757 & 609 & 496 & 796 & 668 & 566 & 768 & 661 & 574 \\
\hline 15 & Cirrhosis & 707 & 555 & 434 & 681 & 559 & 454 & 617 & 511 & 423 \\
\hline 16 & Cirrhosis & 572 & 411 & 304 & 636 & 488 & 382 & 587 & 459 & 359 \\
\hline 17 & Cirrhosis & 582 & 431 & 319 & 581 & 435 & 332 & 582 & 466 & 379 \\
\hline 18 & Cirrhosis & 536 & 358 & 241 & 554 & 401 & 292 & 556 & 407 & 299 \\
\hline 19 & Cirrhosis & 622 & 457 & 337 & 637 & 507 & 401 & 617 & 506 & 414 \\
\hline 20 & Cirrhosis & 814 & 697 & 591 & 746 & 643 & 553 & 709 & 621 & 542 \\
\hline 21 & Cirrhosis & 717 & 564 & 447 & 716 & 582 & 474 & 663 & 542 & 450 \\
\hline 22 & Cirrhosis & 723 & 570 & 439 & 729 & 593 & 478 & 723 & 597 & 484 \\
\hline 23 & Cirrhosis & 813 & 657 & 529 & 783 & 644 & 527 & 726 & 601 & 497 \\
\hline 24 & Cirrhosis & 666 & 498 & 375 & 637 & 482 & 363 & 619 & 482 & 378 \\
\hline 25 & Cirrhosis & 630 & 506 & 405 & 622 & 510 & 419 & 569 & 471 & 388 \\
\hline 26 & Cirrhosis & 652 & 495 & 378 & 619 & 470 & 369 & 607 & 476 & 386 \\
\hline 27 & Cirrhosis & 643 & 486 & 362 & 649 & 517 & 416 & 582 & 475 & 388 \\
\hline 28 & Cirrhosis & 610 & 475 & 369 & 620 & 480 & 376 & 554 & 437 & 347 \\
\hline 29 & Cirrhosis & 747 & 612 & 497 & 719 & 598 & 496 & 696 & 581 & 480 \\
\hline 30 & Cirrhosis & 618 & 469 & 358 & 653 & 528 & 424 & 618 & 507 & 423 \\
\hline 31 & Cirrhosis & 799 & 680 & 587 & 756 & 658 & 570 & 695 & 611 & 537 \\
\hline 32 & Cirrhosis & 579 & 421 & 298 & 583 & 440 & 327 & 589 & 462 & 355 \\
\hline 33 & Cirrhosis & 792 & 635 & 506 & 753 & 609 & 488 & 719 & 596 & 498 \\
\hline 34 & Cirrhosis & 674 & 527 & 414 & 670 & 531 & 421 & 657 & 533 & 437 \\
\hline 35 & Cirrhosis & 715 & 582 & 473 & 728 & 603 & 509 & 596 & 502 & 423 \\
\hline 36 & Cirrhosis & 774 & 635 & 517 & 751 & 623 & 515 & 715 & 594 & 495 \\
\hline 37 & Cirrhosis & 748 & 596 & 464 & 765 & 635 & 527 & 731 & 627 & 531 \\
\hline 38 & Cirrhosis & 514 & 367 & 269 & 513 & 377 & 288 & 518 & 404 & 324 \\
\hline 39 & Cirrhosis & 728 & 582 & 456 & 736 & 611 & 506 & 705 & 577 & 474 \\
\hline 40 & Cirrhosis & 608 & 477 & 375 & 630 & 512 & 416 & 569 & 470 & 388 \\
\hline 41 & Cirrhosis & 637 & 474 & 347 & 638 & 485 & 358 & 639 & 501 & 390 \\
\hline 42 & Cirrhosis & 737 & 609 & 510 & 732 & 617 & 526 & 706 & 612 & 529 \\
\hline 43 & Cirrhosis & 708 & 549 & 423 & 675 & 529 & 405 & 642 & 517 & 412 \\
\hline 44 & Cirrhosis & 544 & 407 & 303 & 511 & 378 & 276 & 506 & 386 & 295 \\
\hline 45 & Normal & 517 & 343 & 237 & 444 & 297 & 210 & 415 & 279 & 187 \\
\hline
\end{tabular}


Table 2 continued

\begin{tabular}{|c|c|c|c|c|c|c|c|c|c|c|}
\hline \multirow[t]{2}{*}{$\begin{array}{l}\text { Sr. } \\
\text { No. }\end{array}$} & \multirow[t]{2}{*}{ Liver } & \multicolumn{3}{|c|}{$\begin{array}{l}\text { LBP radius }=1, \\
\text { matrix }=3 \times 3\end{array}$} & \multicolumn{3}{|c|}{$\begin{array}{l}\text { LBP radius }=2, \\
\text { matrix }=5 \times 5\end{array}$} & \multicolumn{3}{|c|}{$\begin{array}{l}\text { LBP radius }=3 \text {, } \\
\text { matrix }=7 \times 7\end{array}$} \\
\hline & & $\begin{array}{l}3 \text { con- } \\
\text { nected } \\
\text { black } \\
\text { objects }\end{array}$ & $\begin{array}{l}4 \text { con- } \\
\text { nected } \\
\text { black } \\
\text { objects }\end{array}$ & $\begin{array}{l}5 \text { con- } \\
\text { nected } \\
\text { black } \\
\text { objects }\end{array}$ & $\begin{array}{l}3 \text { con- } \\
\text { nected } \\
\text { black } \\
\text { objects }\end{array}$ & $\begin{array}{l}4 \text { con- } \\
\text { nected } \\
\text { black } \\
\text { objects }\end{array}$ & $\begin{array}{l}5 \text { con- } \\
\text { nected } \\
\text { black } \\
\text { objects }\end{array}$ & $\begin{array}{l}3 \text { con- } \\
\text { nected } \\
\text { black } \\
\text { objects }\end{array}$ & $\begin{array}{l}4 \text { con- } \\
\text { nected } \\
\text { black } \\
\text { objects }\end{array}$ & $\begin{array}{l}5 \text { con- } \\
\text { nected } \\
\text { black } \\
\text { objects }\end{array}$ \\
\hline 46 & Normal & 648 & 464 & 333 & 680 & 516 & 391 & 670 & 531 & 423 \\
\hline 47 & Normal & 605 & 428 & 300 & 616 & 444 & 332 & 654 & 511 & 410 \\
\hline 48 & Normal & 582 & 391 & 264 & 477 & 318 & 218 & 418 & 282 & 198 \\
\hline 49 & Normal & 658 & 472 & 333 & 712 & 541 & 427 & 734 & 592 & 482 \\
\hline 50 & Normal & 590 & 391 & 261 & 622 & 450 & 324 & 647 & 489 & 372 \\
\hline
\end{tabular}

Table 3 3, 4 and 5 Connected Counts using DLBP with Otsu method

\begin{tabular}{|c|c|c|c|c|c|c|c|c|c|c|}
\hline \multirow[t]{2}{*}{$\begin{array}{l}\text { Sr. } \\
\text { No. }\end{array}$} & \multirow[t]{2}{*}{ Liver } & \multicolumn{3}{|c|}{$\begin{array}{l}\text { LBP radius }=1 \\
\text { matrix }=3 \times 3\end{array}$} & \multicolumn{3}{|c|}{$\begin{array}{l}\text { LBP radius }=2, \\
\text { matrix }=5 \times 5\end{array}$} & \multicolumn{3}{|c|}{$\begin{array}{l}\text { LBP radius }=3 \\
\text { matrix }=7 \times 7\end{array}$} \\
\hline & & $\begin{array}{l}3 \text { con- } \\
\text { nected } \\
\text { black } \\
\text { objects }\end{array}$ & $\begin{array}{l}4 \text { con- } \\
\text { nected } \\
\text { black } \\
\text { objects }\end{array}$ & $\begin{array}{l}5 \text { con- } \\
\text { nected } \\
\text { black } \\
\text { objects }\end{array}$ & $\begin{array}{l}3 \text { con- } \\
\text { nected } \\
\text { black } \\
\text { objects }\end{array}$ & $\begin{array}{l}4 \text { con- } \\
\text { nected } \\
\text { black } \\
\text { objects }\end{array}$ & $\begin{array}{l}5 \text { con- } \\
\text { nected } \\
\text { black } \\
\text { objects }\end{array}$ & $\begin{array}{l}3 \text { con- } \\
\text { nected } \\
\text { black } \\
\text { objects }\end{array}$ & $\begin{array}{l}4 \text { con- } \\
\text { nected } \\
\text { black } \\
\text { objects }\end{array}$ & $\begin{array}{l}5 \text { con- } \\
\text { nected } \\
\text { black } \\
\text { objects }\end{array}$ \\
\hline 1 & Cirrhosis & 182 & 98 & 50 & 271 & 189 & 127 & 264 & 191 & 136 \\
\hline 2 & Cirrhosis & 153 & 85 & 47 & 235 & 175 & 132 & 218 & 153 & 111 \\
\hline 3 & Cirrhosis & 112 & 74 & 49 & 279 & 202 & 146 & 293 & 213 & 155 \\
\hline 4 & Cirrhosis & 40 & 29 & 21 & 148 & 112 & 92 & 186 & 152 & 122 \\
\hline 5 & Cirrhosis & 208 & 123 & 68 & 189 & 114 & 70 & 165 & 94 & 57 \\
\hline 6 & Cirrhosis & 176 & 90 & 48 & 189 & 109 & 62 & 124 & 58 & 26 \\
\hline 7 & Cirrhosis & 222 & 155 & 110 & 304 & 227 & 171 & 346 & 272 & 217 \\
\hline 8 & Cirrhosis & 154 & 94 & 51 & 233 & 161 & 112 & 232 & 163 & 117 \\
\hline 9 & Cirrhosis & 176 & 107 & 68 & 248 & 184 & 137 & 223 & 155 & 106 \\
\hline 10 & Cirrhosis & 189 & 100 & 56 & 270 & 185 & 127 & 255 & 172 & 114 \\
\hline 11 & Cirrhosis & 212 & 136 & 89 & 255 & 173 & 114 & 270 & 189 & 132 \\
\hline 12 & Cirrhosis & 117 & 77 & 49 & 236 & 177 & 130 & 228 & 164 & 119 \\
\hline 13 & Cirrhosis & 33 & 17 & 10 & 104 & 68 & 44 & 136 & 98 & 71 \\
\hline 14 & Cirrhosis & 121 & 90 & 68 & 237 & 186 & 148 & 245 & 195 & 159 \\
\hline 15 & Cirrhosis & 78 & 51 & 36 & 183 & 131 & 95 & 189 & 136 & 98 \\
\hline 16 & Cirrhosis & 71 & 42 & 27 & 159 & 106 & 77 & 162 & 111 & 79 \\
\hline 17 & Cirrhosis & 90 & 57 & 34 & 165 & 117 & 82 & 159 & 105 & 71 \\
\hline 18 & Cirrhosis & 73 & 38 & 18 & 150 & 85 & 51 & 163 & 98 & 57 \\
\hline 19 & Cirrhosis & 80 & 56 & 40 & 184 & 137 & 105 & 217 & 161 & 125 \\
\hline 20 & Cirrhosis & 113 & 80 & 55 & 232 & 182 & 139 & 292 & 245 & 200 \\
\hline 21 & Cirrhosis & 102 & 60 & 35 & 260 & 183 & 133 & 231 & 170 & 127 \\
\hline 22 & Cirrhosis & 155 & 96 & 56 & 295 & 211 & 138 & 285 & 204 & 142 \\
\hline 23 & Cirrhosis & 156 & 100 & 65 & 310 & 224 & 159 & 263 & 187 & 137 \\
\hline 24 & Cirrhosis & 129 & 76 & 47 & 251 & 170 & 118 & 255 & 172 & 122 \\
\hline 25 & Cirrhosis & 104 & 70 & 45 & 221 & 163 & 118 & 276 & 216 & 170 \\
\hline 26 & Cirrhosis & 132 & 79 & 49 & 259 & 187 & 139 & 243 & 180 & 135 \\
\hline 27 & Cirrhosis & 118 & 76 & 49 & 270 & 209 & 161 & 292 & 229 & 178 \\
\hline 28 & Cirrhosis & 89 & 54 & 32 & 180 & 123 & 85 & 198 & 146 & 110 \\
\hline 29 & Cirrhosis & 141 & 97 & 62 & 293 & 231 & 179 & 294 & 223 & 175 \\
\hline 30 & Cirrhosis & 95 & 71 & 54 & 199 & 146 & 111 & 229 & 171 & 132 \\
\hline 31 & Cirrhosis & 130 & 98 & 74 & 215 & 171 & 137 & 300 & 255 & 222 \\
\hline
\end{tabular}


Table 3 continued

\begin{tabular}{|c|c|c|c|c|c|c|c|c|c|c|}
\hline \multirow[t]{2}{*}{$\begin{array}{l}\text { Sr. } \\
\text { No. }\end{array}$} & \multirow[t]{2}{*}{ Liver } & \multicolumn{3}{|c|}{$\begin{array}{l}\text { LBP radius }=1, \\
\text { matrix }=3 \times 3\end{array}$} & \multicolumn{3}{|c|}{$\begin{array}{l}\text { LBP radius }=2, \\
\text { matrix }=5 \times 5\end{array}$} & \multicolumn{3}{|c|}{$\begin{array}{l}\text { LBP radius }=3, \\
\text { matrix }=7 \times 7\end{array}$} \\
\hline & & $\begin{array}{l}3 \text { con- } \\
\text { nected } \\
\text { black } \\
\text { objects }\end{array}$ & $\begin{array}{l}4 \text { con- } \\
\text { nected } \\
\text { black } \\
\text { objects }\end{array}$ & $\begin{array}{l}5 \text { con- } \\
\text { nected } \\
\text { black } \\
\text { objects }\end{array}$ & $\begin{array}{l}3 \text { con- } \\
\text { nected } \\
\text { black } \\
\text { objects }\end{array}$ & $\begin{array}{l}4 \text { con- } \\
\text { nected } \\
\text { black } \\
\text { objects }\end{array}$ & $\begin{array}{l}5 \text { con- } \\
\text { nected } \\
\text { black } \\
\text { objects }\end{array}$ & $\begin{array}{l}3 \text { con- } \\
\text { nected } \\
\text { black } \\
\text { objects }\end{array}$ & $\begin{array}{l}4 \text { con- } \\
\text { nected } \\
\text { black } \\
\text { objects }\end{array}$ & $\begin{array}{l}5 \text { con- } \\
\text { nected } \\
\text { black } \\
\text { objects }\end{array}$ \\
\hline 32 & Cirrhosis & 103 & 67 & 39 & 224 & 163 & 119 & 252 & 190 & 142 \\
\hline 33 & Cirrhosis & 146 & 95 & 63 & 306 & 228 & 169 & 301 & 223 & 167 \\
\hline 34 & Cirrhosis & 102 & 70 & 49 & 217 & 165 & 125 & 244 & 192 & 154 \\
\hline 35 & Cirrhosis & 151 & 115 & 89 & 297 & 239 & 188 & 290 & 232 & 184 \\
\hline 36 & Cirrhosis & 98 & 59 & 30 & 234 & 174 & 131 & 258 & 197 & 157 \\
\hline 37 & Cirrhosis & 94 & 57 & 31 & 237 & 170 & 120 & 274 & 200 & 145 \\
\hline 38 & Cirrhosis & 117 & 76 & 49 & 242 & 177 & 131 & 241 & 177 & 136 \\
\hline 39 & Cirrhosis & 149 & 93 & 57 & 290 & 209 & 149 & 290 & 218 & 165 \\
\hline 40 & Cirrhosis & 94 & 65 & 44 & 205 & 160 & 129 & 226 & 176 & 145 \\
\hline 41 & Cirrhosis & 100 & 51 & 20 & 211 & 133 & 85 & 267 & 184 & 121 \\
\hline 42 & Cirrhosis & 102 & 80 & 64 & 240 & 199 & 169 & 270 & 227 & 195 \\
\hline 43 & Cirrhosis & 81 & 51 & 28 & 201 & 138 & 96 & 232 & 154 & 107 \\
\hline 44 & Cirrhosis & 105 & 68 & 45 & 193 & 137 & 105 & 186 & 127 & 87 \\
\hline 45 & Normal & 119 & 55 & 28 & 209 & 127 & 78 & 177 & 100 & 54 \\
\hline 46 & Normal & 51 & 24 & 12 & 114 & 68 & 47 & 129 & 79 & 53 \\
\hline 47 & Normal & 33 & 15 & 5 & 79 & 43 & 25 & 81 & 44 & 28 \\
\hline 48 & Normal & 58 & 22 & 8 & 119 & 63 & 36 & 117 & 62 & 32 \\
\hline 49 & Normal & 58 & 28 & 13 & 116 & 68 & 37 & 139 & 92 & 65 \\
\hline 50 & Normal & 37 & 16 & 8 & 107 & 54 & 29 & 127 & 75 & 39 \\
\hline
\end{tabular}

Table 4 3, 4 and 5 connected counts for normal liver and cirrhotic liver using DLBP with Otsu method

\begin{tabular}{|c|c|c|c|c|c|c|}
\hline \multirow[t]{2}{*}{ Counts } & \multicolumn{2}{|l|}{ Radius $=1$} & \multicolumn{2}{|l|}{ Radius $=2$} & \multicolumn{2}{|l|}{ Radius $=3$} \\
\hline & $\begin{array}{l}\text { For normal } \\
\text { liver }\end{array}$ & $\begin{array}{l}\text { For cirrhotic } \\
\text { liver }\end{array}$ & $\begin{array}{l}\text { For normal } \\
\text { liver }\end{array}$ & $\begin{array}{l}\text { For cirrhotic } \\
\text { liver }\end{array}$ & $\begin{array}{l}\text { For normal } \\
\text { liver }\end{array}$ & $\begin{array}{l}\text { For cirrhotic } \\
\text { liver }\end{array}$ \\
\hline $\begin{array}{l}\text { Counts of } 3 \\
\text { connected pixels }\end{array}$ & $0-58$ & Above from 71 & 0-119 & Above from 148 & $0-139$ & $\begin{array}{l}\text { Above from } \\
159\end{array}$ \\
\hline $\begin{array}{l}\text { Counts of } 4 \\
\text { connected pixels }\end{array}$ & $0-28$ & Above from 42 & $0-68$ & Above from 106 & $0-92$ & $\begin{array}{l}\text { Above from } \\
111\end{array}$ \\
\hline $\begin{array}{l}\text { Counts of } 5 \\
\text { connected pixels }\end{array}$ & $0-13$ & Above from 27 & $0-47$ & Above from 62 & $0-65$ & $\begin{array}{l}\text { Above from } \\
79\end{array}$ \\
\hline
\end{tabular}



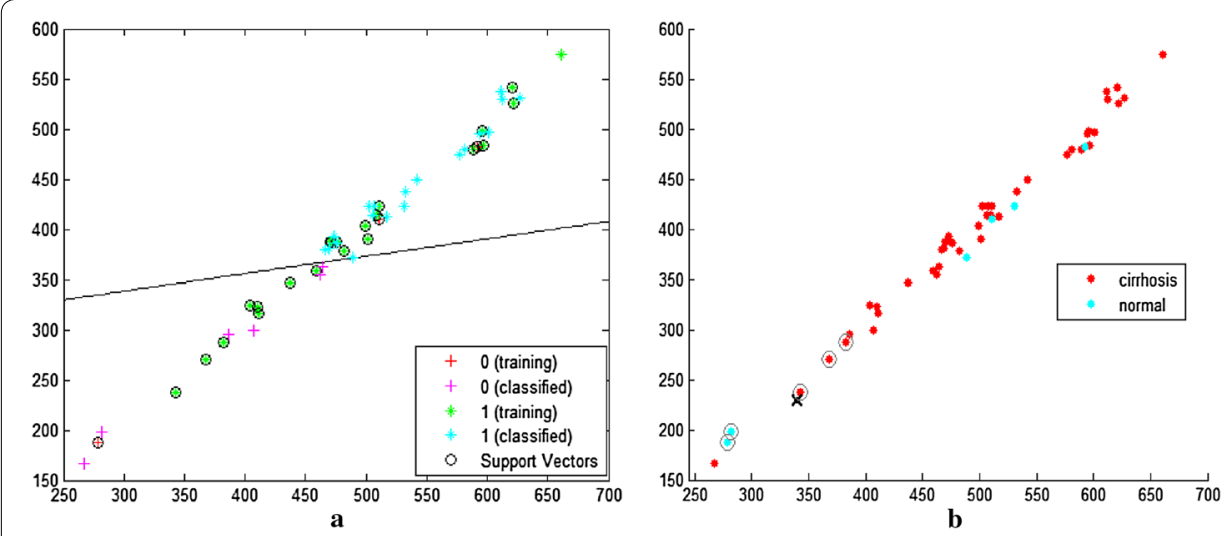

Fig. 6 a SVM classification of OTSU with LBP method, b KNN classification of OTSU with LBP method
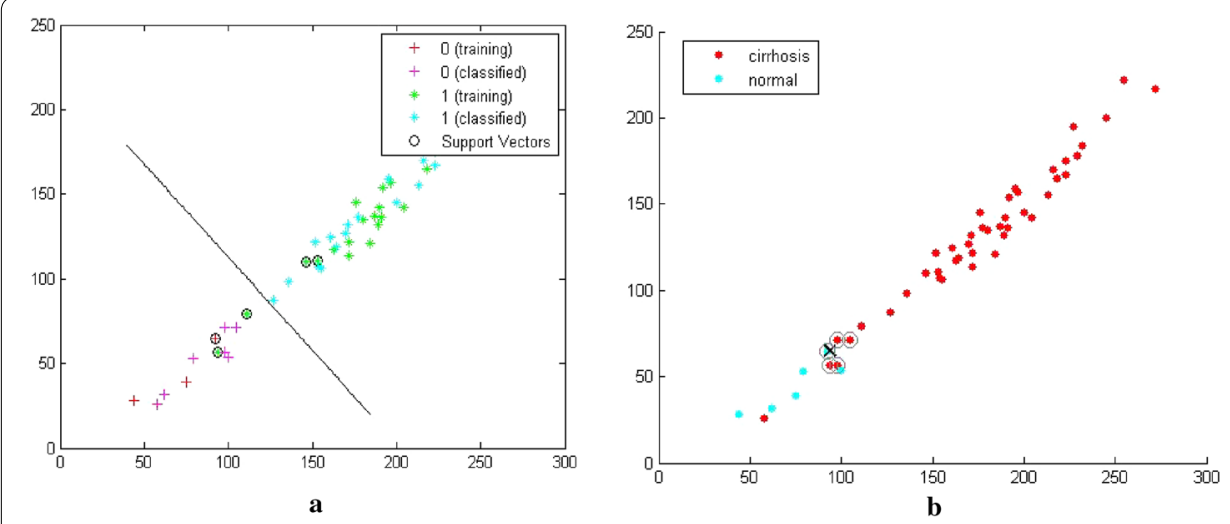

Fig. 7 a SVM classification of OTSU with DLBP method, b KNN classification of OTSU with DLBP method

\section{Authors' contributions}

Our contributions in this paper were that KA carried out the study of image processing, participated in design and analysis and drafted the manuscript. MSB participated in the designing of the technique and performed the statistical analysis. HSR conceived of the study, and participated in its design and coordination and helped to draft the manuscript. All authors read and approved the final manuscript.

\section{Author details}

${ }_{1}^{1}$ Department of Electronics and Communication Engineering, Punjabi University, Patiala, India. ${ }^{2}$ Electronics and Communication Engineering Department, BBSBC, Fatehgarh Sahib, India.

\section{Acknowledgements}

We thank Dr. lla Lynddem Bimbhra, Radiologist, Amar Hospital, Patiala for providing ultrasound image data.

\section{Competing interests}

The authors declare that they have no competing interests.

Received: 16 August 2015 Accepted: 3 March 2016

Published online: 12 March 2016

\section{References}

Ahonen T, Hadid A, Pietikainen M (2004) Face recognition with local binary patterns. In: Proceedings of the European conference on computer vision, pp 469-481

Ali W, Georgsson F, Hellstrom T (2008) Visual tree detection for autonomous navigation in forest environment. In: Proceedings of the IEEE conference on intelligent vehicles symposium, pp 560-565

Brunenberg E, Pujol O, Romeny BH, Radeva P (2006) Automatic IVUS segmentation of atherosclerotic plaque with stop \& go snake. Med Image Comput Comput Assist Interv 4191:9-16

Caballero KL, Barajas J, Pujol O, Salvatella N, Radeva P (2006) In-vivo IVUS tissue classification a comparison between normalized image reconstruction and RF signals. Prog Pattern Recognit Image Anal Appl 4225:137-146 
Castellano G, Bonilha L, Li LM, Cendes F (2004) Texture analysis of medical images. Clin Radiol 59:1061-1069

Chaou AK, Mekhaldi A, Teguar M (2015) Elaboration of novel image processing algorithm for arcing discharges recognition on hv polluted insulator model. IEEE Trans Dielectr Electr Insul 22:990-999

Fauerholdt L, Schlichting P, Christensen E, Poulsen H, Tygstrup N, Juhl E (1983) Conversion of micronodular cirrhosis into macronodular cirrhosis. Hepatology 3:928-931

Filipczuk P, Fevens T, Krzyżak A (2013) Computer-aided breast cancer diagnosis based on the analysis of cytological images of fine needle biopsies. IEEE Trans Med Imaging 32:2169-2178

Fujino K, Mitani Y, Fujita Y, Hamamoto Y, Sakaida I (2014) Liver cirrhosis classification on m-mode ultrasound images by higher-order local auto-correlation features. J Med Bioeng 3:29-32

Fukunage K (1972) Introduction to statistical pattern recognition. Academic Press, NewYork, pp 260-267

Grangier D, Bengio S (2008) A discriminative kernel-based approach to rank images from text queries. IEEE Trans Pattern Anal Mach Intell 30:1371-1384

Hadid A, Pietikainen M, Ahonen T (2004) A discriminative feature space for detecting and recognizing faces. In: Proceedings of the international conference on computer vision pattern recognition, pp 797-804

Hawlick RM (1979) Statistical and structural approaches to texture. Proc IEEE 67:786-808

Heikkila M, Pietikainen M (2006) A texture-based method for modeling the background and detecting moving objects. IEEE Trans Pattern Anal Mach Intell 28:657-662

Hu Y, Zhao C (2010) A local binary pattern based methods for pavement crack detection. J Pattern Recognit Res 1:140-147

Huang DY, Wang CH (2009) Optimal multi-level thresholding using a two-stage Otsu optimization approach. Pattern Recognit Lett 30:275-284

Huijsmans DP, Sebe N (2003) Content-based indexing performance: a class size normalized precision, recall, generality evaluation. In: Proceedings of the international conference on image processing, pp 733-736

Jeong JW, Lee S, Lee JW, Yoo DS, Kim S (2007) The echotextural characteristics for the diagnosis of the liver cirrhosis using the sonographic images. In: Proceedings of the IEEE conference on engineering in medicine and biology society, pp 1343-1345

Kellokumpu V, Zhao G, Pietikainen M (2008) Human activity recognition using a dynamic texture based method. In: Proceedings of the British machine vision conference, Leeds, U.K.

Keramidas EG, lakovidis D, Maroulis D, Karkains S (2007) Efficient and effective ultrasound image analysis scheme for thyroid nodule detection. In: Proceedings of the international conference on image analysis and recognition (ICIAR), vol 4633. Montreal, Canada, pp 1052-1060

Kluckner S, Pacher G, Grabner H, Bischof H (2007) A 3D teacher for car detection in aerial images. In: Proceedings of the IEEE international conference on computer vision, pp 1-8

Lee WL (2013) An ensemble-based data fusion approach for characterizing ultrasonic liver tissue. Appl Soft Comput 13:3683-3692

Lucieer A, Stein A, Fisher P (2005) Multivariate texture-based segmentation of remotely sensed imagery for extraction of objects and their uncertainty. Int J Remote Sens 26:2917-2936

Maenpaa T, Viertola J, Pietikainen M (2003) Optimising colour and texture features for real-time visual inspection. Pattern Anal Appl 6:169-175

Mitrea D, Nedevschi S, Badea R (2012) The role of the multiresolution textural features in improving the characterization and recognition of the liver tumors, based on ultrasound images. In: Proceedings of the international symposium on symbolic and numeric algorithms for scientific computing, pp 192-199

Murala S, Jonathan QM (2014) Local mesh patterns versus local binary patterns: biomedical image indexing and retrieval. IEEE J Biomed Health Inf 18:929-938

Nanni L, Lumini A (2008) Ensemble of multiple pedestrian representations. IEEE Trans Intell Transp Syst 9:365-369

NIDDK (2010) Cirrhosis. National Institute of Diabetes and Digestive and Kidney Diseases. http://digestive.niddk.nih.gov/ ddiseases/pubs/cirrhosis_ez

Ojala T, Pietikainen M, Harwood D (1996) A comparative study of texture measures with classification based on featured distribution. Pattern Recognit 29:51-59

Ojala T, Pietikainen M, Maenpaa T (2002) Multiresolution gray-scale and rotation invariant texture classification with local binary patterns. IEEE Trans Pattern Anal Mach Intell 24:971-987

Oliver A, Llado X, Freixenet J, Marti J (2007) False positive reduction in mammographic mass detection using local binary patterns. In: Proceedings of the international conference on medical image computing and computer assisted intervention, pp 286-293

Otsu N (1979) A threshold selection method from gray-level histograms. IEEE Trans Syst Man Cybern 9:62-66

Pujol O, Rotger D, Radeva P, Rodriguez O, Mauri I (2003) Near real-time plaque segmentation of IVUS. Comput Cardiol 30:69-72

Rodríguez R (2006) A strategy for blood vessels segmentation based on the threshold which combines statistical and scale space filter: application to the study of angiogenesis. Comput Methods Programs Biomed 82:1-9

Tamim A, Minaoui K, Daoudi K, Yahia H, Atillah A, Aboutajdine D (2015) An efficient tool for automatic delimitation of Moroccan coastal upwelling using SST images. IEEE Geosci Remote Sens Lett 12:875-879

Turtinen M, Pietikainen M, Silven O (2006) Visual characterization of paper using isomap and local binary patterns. IEICE Trans Inf Syst E89D:2076-2083

Virmani J, Kumar V, Kalra N, Khandelwal N (2011) Prediction of cirrhosis based on singular value decomposition of gray level co-occurence matrix and a neural network classifier. In: Proceedings of the IEEE international conference on developments in e-systems engineering, pp 146-151

Virmani J, Kumar V, Kalra N, Khandelwal N (2013) SVM-based characterization of liver ultrasound images using wavelet packet texture descriptors. Springer J Digit Imaging 26:530-543

WHO (2015) Hepatitis C. World Health Organization. http://www.who.int/mediacentre/factsheets/fs164/en

Wu CC, Lee WL, Chen YC, Lai CH, Hsieh KS (2012) Ultrasonic liver tissue characterization by feature fusion. Expert Syst Appl 39:9389-9397

Wu CC, Lee WL, Chen YC, Hsieh KS (2013) Evolution-based hierarchical feature fusion for ultrasonic liver tissue characterization. IEEE J Biomed Health Inf 17:967-976 